\title{
Imaging alternatives to colonoscopy: CT colonography and colon capsule. European Society of Gastrointestinal Endoscopy (ESGE) and European Society of Gastrointestinal and Abdominal Radiology (ESGAR) Guideline - Update 2020
}

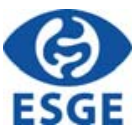

Authors

Cristiano Spada ${ }^{1,2}$, Cesare Hassan ${ }^{3}$, Davide Bellini ${ }^{4}$, David Burling ${ }^{5}$, Giovanni Cappello ${ }^{6}$, Cristina Carretero ${ }^{7}$, Evelien Dekker $^{8}$, Rami Eliakim ${ }^{9}$, Margriet de Haan ${ }^{10}$, Michal F. Kaminski11, Anastasios Koulaouzidis ${ }^{12}$, Andrea Laghi ${ }^{13}$, Philippe Lefere ${ }^{14}$, Thomas Mang ${ }^{15}$, Sebastian Manuel Milluzzo ${ }^{1,2}$, Martina Morrin ${ }^{16}$, Deirdre McNamara ${ }^{17}$, Emanuele Neri $^{18}$, Silvia Pecere ${ }^{2}$, Mathieu Pioche ${ }^{19}$, Andrew Plumb ${ }^{20}$, Emanuele Rondonotti ${ }^{21}$, Manon CW Spaander ${ }^{22}$, Stuart Taylor $^{20}$, Ignacio Fernandez-Urien ${ }^{23}$, Jeanin E. van Hooft ${ }^{24}$, Jaap Stoker ${ }^{25}$, Daniele Regge ${ }^{6,26}$

Institutions

1 Digestive Endoscopy Unit and Gastroenterology, Fondazione Poliambulanza, Brescia, Italy

2 Department of Gastroenterology, Fondazione Policlinico Universitario A. Gemelli IRCCS, Università Cattolica del Sacro Cuore, Rome, Italy

3 Gastroenterology Unit, Nuovo Regina Margherita Hospital, Rome, Italy

4 Department of Radiological Sciences, Oncology and Pathology, La Sapienza University of Rome, Diagnostic Imaging Unit, I.C.O.T. Hospital Latina, Italy

5 St. Mark's Hospital, Harrow, London, UK

6 Radiology Unit, Candiolo Cancer Institute, FPO-IRCCS, Candiolo, Turin, Italy

7 Department of Gastroenterology. University of Navarre Clinic, Healthcare Research Institute of Navarre, Pamplona, Spain

8 Department of Gastroenterology and Hepatology, Amsterdam University Medical Center location AMC, The Netherlands

9 Department of Gastroenterology, Sheba Medical Center, Sackler School of Medicine, Tel-Aviv, Israel

10 Department of Radiology, University Medical Center, Utrecht, The Netherlands

11 Departments of Gastroenterological Oncology and Cancer Prevention, The Maria Sklodowska-Curie National Research Institute of Oncology, Warsaw, Poland

12 Endoscopy Unit, Centre for Liver and Digestive Disorders, University Hospitals, NHS Lothian, Edinburgh, UK

13 Department of Surgical-Medical Sciences and Translational Medicine, La Sapienza University of Rome, Italy
14 Department of Radiology, Stedelijk Ziekenhuis, Roeselare, Belgium

15 Department of Biomedical Imaging and Image-guided Therapy, Medical University of Vienna, Vienna, Austria

16 RCSI Radiology, Royal College of Surgeons in Ireland, Dublin, Ireland

17 TAGG Research Centre, Department of Clinical Medicine, Trinity Centre, Tallaght Hospital, Dublin, Ireland

18 Diagnostic Radiology 3, Department of Translational Research, University of Pisa, Italy

19 Endoscopy and Gastroenterology Unit, Edouard Herriot Hospital, Hospices Civils de Lyon, Lyon, France

20 Centre for Medical Imaging, University College London, London, UK

21 Gastroenterology Unit, Ospedale Valduce, Como, Italy

22 Department of Gastroenterology and Hepatology, Erasmus University Medical Center, Rotterdam, the Netherlands

23 Gastroenterology, Hospital de Navarra, Pamplona, Spain

24 Department of Gastroenterology and Hepatology, Leiden University Medical Center, The Netherlands

25 Radiology and Nuclear Medicine, Amsterdam University Medical Centers, Amsterdam, The Netherlands

26 University of Turin Medical School, Turin, Italy

This article is published simultaneously in the journals Endoscopy (doi 10.1055/a-1258-4819) and European Radiology (doi: 10.1007/s00330-020-07413-4).

Copyright 2020 @ Thieme and (c) European Society of Radiology.

published online 26.10 .2020 
Bibliography

Endoscopy 2020; 52: 1127-1141

DOI 10.1055/a-1258-4819

ISSN 0013-726X

(C) 2020. Thieme. All rights reserved.

Georg Thieme Verlag KG, Rüdigerstraße 14,

70469 Stuttgart, Germany

Corresponding author

Cristiano Spada, MD PhD, Digestive Endoscopy Unit and Gastroenterology, Fondazione Poliambulanza, Via Bissolati, 57, Brescia, Italy

cristianospada@gmail.com

丹 Supplementary material

Supplementary material is available under

https://doi.org/10.1055/a-1258-4819

\section{MAIN RECOMMENDATIONS}

1 ESGE/ESGAR recommend computed tomographic colonography (CTC) as the radiological examination of choice for the diagnosis of colorectal neoplasia.

Strong recommendation, high quality evidence.

ESGE/ESGAR do not recommend barium enema in this setting.

Strong recommendation, high quality evidence.

2 ESGE/ESGAR recommend CTC, preferably the same or next day, if colonoscopy is incomplete. The timing depends on an interdisciplinary decision including endoscopic and radiological factors.

Strong recommendation, low quality evidence.

ESGE/ESGAR suggests that, in centers with expertise in and availability of colon capsule endoscopy (CCE), CCE preferably the same or the next day may be considered if colonoscopy is incomplete.

Weak recommendation, low quality evidence.

3 When colonoscopy is contraindicated or not possible, ESGE/ESGAR recommend CTC as an acceptable and equally sensitive alternative for patients with alarm symptoms.

Strong recommendation, high quality evidence.

Because of lack of direct evidence, ESGE/ESGAR do not recommend CCE in this situation.

Very low quality evidence.

ESGE/ESGAR recommend CTC as an acceptable alternative to colonoscopy for patients with non-alarm symptoms. Strong recommendation, high quality evidence.

In centers with availability, ESGE/ESGAR suggests that CCE may be considered in patients with non-alarm symptoms. Weak recommendation, low quality evidence.
4 Where there is no organized fecal immunochemical test (FIT)-based population colorectal screening program, ESGE/ESGAR recommend CTC as an option for colorectal cancer screening, providing the screenee is adequately informed about test characteristics, benefits, and risks, and depending on local service- and patient-related factors.

Strong recommendation, high quality evidence.

ESGE/ESGAR do not suggest CCE as a first-line screening test for colorectal cancer.

Weak recommendation, low quality evidence.

5 ESGE/ESGAR recommend CTC in the case of a positive fecal occult blood test (FOBT) or FIT with incomplete or unfeasible colonoscopy, within organized population screening programs.

Strong recommendation, moderate quality evidence.

ESGE/ESGAR also suggest the use of CCE in this setting based on availability.

Weak recommendation, moderate quality evidence.

6 ESGE/ESGAR suggest CTC with intravenous contrast medium injection for surveillance after curative-intent resection of colorectal cancer only in patients in whom colonoscopy is contraindicated or unfeasible

Weak recommendation, low quality evidence.

There is insufficient evidence to recommend CCE in this setting.

Very low quality evidence.

7 ESGE/ESGAR suggest CTC in patients with high risk polyps undergoing surveillance after polypectomy only when colonoscopy is unfeasible.

Weak recommendation, low quality evidence.

There is insufficient evidence to recommend CCE in postpolypectomy surveillance.

Very low quality evidence.

8 ESGE/ESGAR recommend against CTC in patients with acute colonic inflammation and in those who have recently undergone colorectal surgery, pending a multidisciplinary evaluation.

Strong recommendation, low quality evidence.

9 ESGE/ESGAR recommend referral for endoscopic polypectomy in patients with at least one polyp $\geq 6 \mathrm{~mm}$ detected at CTC or CCE.

Follow-up CTC may be clinically considered for 6-9-mm CTC-detected lesions if patients do not undergo polypectomy because of patient choice, comorbidity, and/or low risk profile for advanced neoplasia.

Strong recommendation, moderate quality evidence. 


$\begin{array}{ll}\text { ABBREVIATIONS } \\ \begin{array}{ll}\text { ANDR } & \text { advanced neoplasia detection rate } \\ \text { CCE } & \text { colon capsule endoscopy (CCE-1, first genera- } \\ & \text { tion; CCE-2, second generation) } \\ \text { CT } & \text { computed tomography } \\ \text { CTC } & \text { computed tomographic colonography } \\ \text { DCBE } & \text { double-contrast barium enema } \\ \text { ECCO } & \text { European Cancer Organisation } \\ \text { ECF } & \text { extracolonic finding } \\ \text { ESGAR } & \text { European Society of Gastrointestinal and } \\ & \text { Abdominal Radiology } \\ \text { ESGE } & \text { European Society of Gastrointestinal Endoscopy } \\ \text { FIT } & \text { fecal immunochemical test } \\ \text { FOBT } & \text { fecal occult blood test } \\ \text { GRADE } & \text { Grading of Recommendations Assessment, } \\ & \text { Development and Evaluation } \\ \text { IBD } & \text { inflammatory bowel disease } \\ \text { NPV } & \text { negative predictive value } \\ \text { OR } & \text { odds ratio } \\ \text { PEG } & \text { polyethylene glycol } \\ \text { PICO } & \text { population, intervention, comparison/control, } \\ & \text { outcome } \\ \text { PPV } & \text { positive predictive value } \\ \text { RCT } & \text { randomized controlled trial } \\ \text { SIGGAR } & \text { Special Interest Group in Gastrointestinal and } \\ & \text { Abdominal Radiology }\end{array} \\ & \\ & \end{array}$

\section{SOURCE AND SCOPE}

This is an update of the 2014-15 Guideline of the European Society of Gastrointestinal Endoscopy (ESGE) and the European Society of Gastrointestinal and Abdominal Radiology (ESGAR). It addresses the clinical indications for the use of imaging alternatives to standard colonoscopy. A targeted literature search was performed to evaluate the evidence supporting the use of computed tomographic colonography (CTC) or colon capsule endoscopy (CCE). The Grading of Recommendations Assessment, Development and Evaluation (GRADE) system was adopted to define the strength of recommendations and the quality of evidence.

\section{Introduction}

Colorectal cancer represents a major cause of cancer-related morbidity and mortality in European countries [1]. Colonoscopy has a pivotal role in early diagnosis and colorectal cancer prevention because of its high accuracy for detection of precancerous lesions as well as the possibility to remove them [2-6]. Despite incremental technical improvement, colonoscopy is still incomplete in a proportion of patients due to patient and/or endoscopist-related factors. Furthermore, patients

may be reluctant to undergo a procedure, namely colonoscopy, that is still perceived as painful, despite the availability of sedation or anesthesia [7].

Computed tomographic colonography (CTC) and colon capsule endoscopy (CCE) have been proposed as alternative imaging modalities to explore the colonic mucosa. CTC is a noninvasive imaging method that uses computed tomography for data acquisition combined with specialized imaging software to examine the colon $[8,9]$. CCE, introduced several years later [10], is a painless and radiation-free alternative for the study of the entire colon, in which an ingestible, wireless, disposable capsule is used to explore the colon without sedation or gas insufflation.

In this document, the European Society of Gastrointestinal Endoscopy (ESGE) and the European Society of Gastrointestinal and Abdominal Radiology (ESGAR) have updated the previously published guidelines on CTC [11] and CCE [12] and incorporated new evidence.

\section{Methods}

ESGE and ESGAR commissioned the update of this guideline and appointed two guideline leaders (C.S., D.R.), who invited the listed authors to participate in the project development. The key questions were prepared by the coordinating team using PICO methodology (population, intervention, comparison/control, outcome) [13] and were then approved by the other members. The coordinating team formed task force subgroups, based on the statements of the previous guideline, each with its own leader, and divided the key topics among these task forces (Appendix $1 \mathbf{s}$, see online-only Supplementary Material) with a specific focus on the update of literature and revision of the statements. The work included telephone conferences, a face-to-face meeting and online discussions.

The task forces conducted a literature search using Medline (via Pubmed) and the Cochrane Central Register of Controlled Trials up to November 2019. New evidence on each key question was summarized in tables using the Grading of Recommendations Assessment, Development and Evaluation (GRADE) system [14]. Grading depends on the balance between the benefits and risk or burden of any health intervention [15] (Appendix 2 s). Further details on ESGE guideline development have been reported elsewhere [16].

This Guideline applies only to patients undergoing screening or with suspicion of colorectal neoplasia, whilst the role of these techniques in inflammatory bowel disease (IBD) is outside the purpose of this guideline. Technical issues for each technique are considered in Appendix $3 \mathrm{~s}$.

The results of the search and guideline statements were presented to all members of the project group during a faceto-face meeting in Vienna, Austria on November 4th, 2019, and were voted on. Consensus was defined as an agreement of at least $80 \%$ (Appendix $\mathbf{4 s}$ ). If consensus was not reached during the first voting session, agreement was sought after further discussion and the modified statement was voted on again, until consensus was reached. After this meeting, drafts were 
made by the chairs of each task force and distributed between the task force members for revision.

In February 2020, a draft prepared by C.S. and D.R. and the chairs of all the task forces was sent to all group members. After agreement of all members, the manuscript was reviewed by two external reviewers and was sent for further comments to the ESGE and ESGAR national societies and individual members. After this, the manuscript was submitted to the journals European Radiology and Endoscopy for publication. The final revised manuscript was agreed upon by all the authors. This Guideline was issued in 2020 and will be considered for update in 2025. Any interim updates will be noted on the ESGE website: http:// www.esge.com/esge-guidelines.html.

The Appraisal of Guidelines, Research and Evaluation (AGREE) checklist is provided in Appendix 5 s.

\section{Radiological imaging for the diagnosis of colorectal neoplasia}

\section{RECOMMENDATION}

ESGE/ESGAR recommend CTC as the radiological examination of choice for the diagnosis of colorectal neoplasia. Strong recommendation, high quality evidence. ESGE/ESGAR do not recommend barium enema in this setting.

Strong recommendation, high quality evidence.

CTC has been considered the best radiological examination for the diagnosis of colorectal neoplasia. The accuracy for both colorectal cancer and large/advanced polyps has shown to be similar to that of optical colonoscopy in symptomatic and asymptomatic patients and clearly superior to that of barium enema [11].

The literature review provides further evidence to support this statement. Two new European randomized trials $[17,18]$ and an evaluation of follow-up [19] have shown detection rates for advanced neoplasia being similar to those of optical colonoscopy in asymptomatic individuals invited for screening. A systematic review has shown the rate of interval cancers after a negative CTC (4.5\%) compares favorably with that following optical colonoscopy (3\%-9\%) [20]. In a Japanese multicenter trial, including 1177 patients, sensitivities and specificities of over $90 \%$ were achieved for detection of colorectal neoplasia $>9 \mathrm{~mm}$ by CTC [21].

CTC is superior to double-contrast barium enema (DCBE) for detection of colorectal cancer and large polyps [22]. A review of the recent literature shows no new studies that specifically evaluated the performance of DCBE for the detection of colorectal neoplasia, nor does it provide new evidence supporting the primary use of DCBE for this indication. The continuing decrease in the use of DCBE [21] may further negatively affect its performance quality. Barium studies have also been mainly replaced by either endoscopic or cross-sectional imaging techniques for the evaluation of non-neoplastic conditions such as inflammatory bowel disease (IBD) [23].

Water-soluble contrast enemas are, however, still used in clinical practice for a relatively narrow spectrum of indications. These indications include mainly imaging of post-surgical sites and detection of anastomotic leaking. They vary, depending on local experience and clinical practice. Some of these indications, however, are debated.

\section{Completion of a previously incomplete colonoscopy}

\section{RECOMMENDATION}

ESGE/ESGAR recommend CTC, preferably the same or next day, if colonoscopy is incomplete. The timing depends on an interdisciplinary decision including endoscopic and radiological factors.

Strong recommendation, low quality evidence.

ESGE/ESGAR suggests that, in centers with expertise in and availability of CCE, CCE preferably the same or the next day may be considered if colonoscopy is incomplete. Weak recommendation, low quality evidence.

\section{Incomplete colonoscopy for neoplastic lesions - CTC}

Almost all cases of incomplete optical colonoscopy due to occlusive cancer can be examined successfully with CTC [24, 25] and one study showed that preoperative CTC, after an incomplete optical colonoscopy, contributed to a change in the surgical plan in 14 of 65 patients (21.5\%). Up to $35.1 \%$ (range $22.3 \%-45.4 \%$ ) of synchronous neoplasms occur in one or more different segments from the distal tumor so their detection will change management in a significant number of patients [26].

\section{Incomplete colonoscopy for non-neoplastic lesions-CTC}

Abdominal symptoms may be due to non-neoplastic colonic conditions, for which both CTC and colonoscopy may be useful. Diverticulosis is more commonly demonstrated at CTC than colonoscopy [27], although the relationship between diverticulosis and symptoms is less clear. Colonoscopy is more sensitive for the detection of colitis and anal pathology [27]; furthermore it offers the possibility of tissue sampling.

In non-obstructing lesions, colonoscopy should be the preferred modality [28]. Colonoscopy allows biopsies and removal of most benign lesions during the same procedure. If active colitis is identified at incomplete colonoscopy, it is reasonable to repeat colonoscopy to facilitate serial colonic biopsies. Moreover, areas of colitis-related dysplasia will be missed at CTC. If there is an obstructing lesion, it is reasonable to refer for CTC.

In the setting of incomplete colonoscopy because of factors such pelvic postoperative adhesions, strictures due to diverticular disease/inflammatory processes, and/or refractory looping, colonoscopy is less likely to be successful. If pain/spasm is 
the main reason for incomplete colonoscopy, then either repeating the procedure with more sedation or CTC are both reasonable options.

\section{Timing of CTC after incomplete colonoscopy}

The timing of CTC after incomplete colonoscopy depends on an interdisciplinary decision including endoscopic and radiological factors. O'Shea et al. [29] recently assessed 245 same-day, post-incomplete colonoscopy CTC studies, with routine bowel preparation and $30 \mathrm{ml}$ diatrizoate tagging agent. The mean time from ingestion of tagging agent to CTC was 4 hours 26 minutes. Contrast reached the left hemicolon in $84 \%$ of patients; and $99 \%$ of studies were considered diagnostically adequate. The effectiveness of reduced 2-hour iodinated contrast preparation was evaluated by Chang et al. [30] who found that a reduced 2-hour iodinated preparation failed to reach the left hemicolon in $26 \%$ of patients. Although Theis et al. [31] suggest that separate CTC is superior for this reason, the vast majority of patients can have a diagnostic study when same-day CTC is performed with a minor increase in the time interval between optical colonoscopy and CTC. In situations where the left hemicolon has been well visualized by optical colonoscopy, the same consideration could be given to reduced preparation time; a thought echoed by other authors [32].

Clinically suspected perforation, possibly moderate/severe diverticulitis, or moderate/severe colitis are contraindications to same-day CTC $[29,33]$. Same-day CTC may be ill-advised after hot snare (snare cautery) or endoscopic mucosal resection (EMR). Lara et al. [34] looked at 198 patients who had same-day CTC (3\% of 6260 colonoscopies). They found that 72 polypectomies had been performed in 34 patients (17\%). There were no reported complications or perforations associated with same-day CTCs, suggesting that CTC is safe when performed on the same day as the procedure.

\section{Incomplete colonoscopy-CCE}

(See also Appendix 6s)

In the case of non-neoplastic obstruction, CCE can be considered as an alternative to CTC to explore proximal colonic segments. Seven studies using second-generation CCE (CCE-2) have been reported in the literature. Overall, visualization of colonic segments not reached by previous colonoscopy was obtained in $75 \%-100 \%$ of cases with CCE-2 [35-41] and $85 \%-$ $93 \%$ with first-generation CCE (CCE-1) [42-44], with significant findings in $24 \%-100 \%$ in CCE-2 studies, and $34 \%-59 \%$ in CCE-1 studies.

Spada et al. [39] in a prospective, single-blinded, head-tohead study compared CTC with CCE in patients with incomplete colonoscopy. In this study, CCE identified $\geq 6$-mm polyps in $24.5 \%$ of patients $(95 \% \mathrm{Cl} 16.6 \%-34.4 \%)$ and CTC in $12.2 \%$ $(95 \% \mathrm{Cl} 6.8 \%-20.8 \%)$, with a relative sensitivity of $2.0(95 \% \mathrm{Cl}$ $1.34-2.98)$, which indicated a significant increase in sensitivity for lesions $\geq 6 \mathrm{~mm}$ when using CCE. Stratifying the analysis for larger polyps, CCE detected $\geq 10$-mm polyps in $5.1 \%$ of patients (95\% Cl $1.9 \%-12.1 \%)$ and CTC in $3.1 \%(95 \% \mathrm{Cl} 0.8 \%-9.3 \%)$, with a relative sensitivity of $1.67(95 \% \mathrm{Cl} 0.69-4.00)$. Both pro- cedures, namely CTC and CCE, showed similar high positive predictive values (PPVs).

\section{Timing of CCE after incomplete colonoscopy}

The optimal timing of CCE after incomplete colonoscopy is still unclear. Two studies analyzed the possibility of performing CCE on the same day after an incomplete colonoscopy. Hussey et al. [36] used sodium phosphate booster plus $1 \mathrm{~L}$ of gastrografin to perform CCE-2 on the same day after the incomplete colonoscopy, with an overall completion rate of $76 \%$, a full colonic visualization in $84 \%$, and a mean colon passage time of 233 minutes. Image quality was considered suboptimal in $9 \%$ of patients.

In the other study, Triantafyllou et al. [42] used $1 \mathrm{~L}$ polyethylene glycol (PEG) plus 2 tablets of domperidone as bowel preparation and sodium phosphate as booster to perform CCE-1 the same day after the incomplete colonoscopy. The overall completion rate was $90.7 \%$, while a complete colonic visualization was obtained in $76 \%$ of patients. Quality of preparation was considered adequate in $60.3 \%$ and $63.4 \%$ in the right and left colonic segments, respectively.

\section{Patients with symptoms suggestive of colorectal cancer}

\section{RECOMMENDATION}

When colonoscopy is contraindicated or not possible, ESGE/ESGAR recommend CTC as an acceptable and equally sensitive alternative for patients with alarm symptoms suggestive of colorectal cancer.

Strong recommendation, high quality evidence.

Due to lack of direct evidence, ESGE/ESGAR do not recommend CCE in this situation.

Very low quality evidence.

ESGE/ESGAR recommend CTC as an acceptable alternative to colonoscopy for patients with non-alarm symptoms. Strong recommendation, high quality evidence. In centers with availability, ESGE/ESGAR suggests that CCE may be considered in patients with non-alarm symptoms. Weak recommendation, low quality evidence.

Patients with abdominal symptoms suggestive of colorectal cancer require detailed investigation, since neither clinical examination nor fecal testing reliably excludes colorectal cancer [45]. The ideal test would also diagnose non-neoplastic conditions responsible for the symptoms (both within the colon and/or extracolonic).

\section{Colorectal neoplasia detection - CTC}

In a recent meta-analysis including 34 studies for a total of 41680 participants, CTC sensitivity for detection of colorectal cancer was $93 \%$ among older patients (>65 years) and $92 \%$ among younger patients [46]. These data and the results of the Special Interest Group in Gastrointestinal and Abdominal 
Radiology (SIGGAR) trial [27] suggest that CTC and colonoscopy have similar sensitivity for detecting colorectal cancer and large polyps in symptomatic patients. Small polyps $(6-9 \mathrm{~mm})$ and diminutive polyps $(\leq 5 \mathrm{~mm})$ are less relevant in symptomatic patients, since they cannot explain the patient's symptoms.

\section{Extracolonic findings (ECFs)}

ECFs are common in symptomatic patients. A recent meta-analysis [47] reported an incidence of potentially significant ECFs of $5.2 \%$ in a cohort with symptoms and of $2.8 \%$ in a cohort of patients without symptoms. In patients with ECFs, the rate of recommended further work-up was $8.2 \%$. In the SIGGAR trial $59.6 \%$ of patients had at least one extracolonic finding at CTC and the proportion increased with age; a total of 149 patients (8.5\%) underwent further work-up. In the same trial [22], significantly more patients randomized to CTC underwent additional investigation than colonoscopy (30\% vs. $8.2 \%$; $P<0.001)$ raising concerns of additional costs for CTC. However, of the 1634 patients that underwent CTC, 72 (4.4\%) were diagnosed with extracolonic malignancy. Overall in the SIGGAR trial, total costs of CTC and colonoscopy were similar [48].

\section{Colorectal neoplasia detection - CCE}

Few studies evaluated the role of CCE in patients at high risk for colorectal cancer, with abdominal or alarm symptoms (rectal bleeding, anemia, weight loss, intestinal subocclusion). One prospective, single-center study [41] included 67 patients at risk of colorectal cancer, unable or unwilling to undergo colonoscopy, who underwent CCE. Colonic and ECFs were detected in 23 patients $(34 \%, 95 \% \mathrm{Cl} 21.6 \%-44.1 \%)$. Of these, six patients were diagnosed with cancer, comprising 4 colon cancers, 1 gastric cancer, and 1 small-bowel cancer. The CCE findings were confirmed after surgery in all patients.

CCE might be considered as an alternative diagnostic tool in this setting. However, the evidence was considered insufficient to recommend CCE in patients with alarm symptoms. In patients with non-alarm symptoms [49] CCE can be considered, this being a weak recommendation.

\section{CTC and CCE and screening for colorectal cancer}

\section{RECOMMENDATION}

Where there is no organized fecal immunochemical test (FIT)-based population colorectal screening program, ESGE/ESGAR recommend CTC as an option for colorectal cancer screening, providing the screenee is adequately informed about test characteristics, benefits, and risks, and depending on local service- and patient-related factors.

Strong recommendation, high quality evidence.

ESGE/ESGAR do not suggest CCE as a first-line screening test for colorectal cancer.

Weak recommendation, low quality evidence.

\section{CTC in screening: participation}

Between 2009 and 2014 three European randomized population screening trials have been performed. These trials respectively compared primary CTC screening testing to colonoscopy (Colonoscopy or Colonography for Screening [COCOS] trial [50], and the SAVE trial [17]), to sigmoidoscopy (the PROTEUS trial [18]) and to FIT (SAVE [17]). Participation rates were: $34 \%$ and $22 \%$ for CTC and colonoscopy, respectively, in the COCOS trial; $30 \%$ and $27 \%$ for CTC and sigmoidoscopy, respectively, in the PROTEUS trial; and $28 \%$ and $50 \%$ respectively for CTC and FIT in the SAVE trial. In the PROTEUS trials, participation was higher in men than in women (35\% vs. $27 \%$ ). Invitation and preparation modalities, which differed between trials, may have affected participation rates [51].

In the COCOS trial almost half of the nonparticipants made an informed decision on participation as they were provided with adequate knowledge of colorectal cancer and colorectal cancer screening, and showed a positive attitude towards screening, but nevertheless declined participation; this suggested that additional barriers to participation were present [50]. In the PROTEUS trial the two main factors affecting participation were screening-related anxiety and belief that screening is ineffective [52].

\section{CTC in screening: detection rate and yield}

In the COCOS trial, advanced neoplasia detection rate (ANDR) per 100 participants was lower for CTC than colonoscopy (6.1 persons vs. 8.7) [50]. However, 6-9-mm polyps detected by CTC underwent surveillance, and with subsequent resections the ANDR for CTC (8.6\%) was similar to that of colonoscopy [53]. In the SAVE trial, the CTC ANDR was 4.9-5.5 (depending on bowel preparation) versus 7.2 for colonoscopy, and 1.7 for one round of FIT [17]. In the PROTEUS trial, CTC ANDR was similar to that of sigmoidoscopy (5.1 vs. 4.7 per 100 participants) [18].

However, due to higher CTC participation, in the COCOS trial, ANDR per 100 invitees for CTC (2.1) was similar to that of colonoscopy (1.9), and higher (2.9\%) when 6-9-mm polyps were included. A slightly higher per-invitee ANDR was also observed for CTC compared with colonoscopy in the SAVE trial (1.4 vs. 1.1 per 100 invitees) and compared with sigmoidoscopy in the PROTEUS trial (1.6 vs. 1.3 invitees).

In the case of serrated adenomas, the diagnostic yield of colonoscopy was 5 times higher than that of CTC. This is relevant, since approximately $10 \%-20 \%$ of colorectal cancer develops from the serrated pathway [54].

The PROTEUS trial also reported a lower ANDR for CTC in the distal colon compared with sigmoidoscopy (2.9\% vs. $3.9 \%)$.

\section{Acceptability of CTC screening}

As noted above, randomized controlled trial (RCT) data suggests that in general, participation rates for CTC are higher than for colonoscopy or sigmoidoscopy. In the PROTEUS trial, only a small percentage of attendees would not recommend CTC to friends or relatives $(6.7 \%)$ and would not repeat the test in the future if invited (7.2\%) [52]. However, these rates 
were significantly higher than in the flexible sigmoidoscopy arm. Bowel preparation was considered the most negative aspect of the process, with $17.9 \%$ having moderate or severe discomfort, and pain being perceived by $16.8 \%$. Sali et al. [55] reported no preparation-related symptoms in $88 \%$ of interviewed screenees undergoing reduced bowel preparation compared to $70 \%$ of those undergoing full bowel preparation and an improved participation rate in the former group.

\section{Safety of CTC screening}

\section{Adverse events}

The risk of major adverse events due to the CTC examination itself (including the bowel preparation) is low and likely lower than for colonoscopy [27, 56-58]. In a meta-analysis [59] including 103399 asymptomatic and symptomatic patients, the CTC overall perforation rate was estimated to be $0.04 \%$; the rate was 19 -fold higher in symptomatic compared with screening individuals. In a randomized trial comparing CTC with colonoscopy screening, serious adverse events were comparable for both procedures ( $0.2 \%$ for CTC; $0.3 \%$ for colonoscopy) [50]. Adverse events of CTC screening should also take into account those related to colonoscopy following a positive result; it would be expected that these would be similar to those observed in randomized trials of fecal occult blood testing (FOBT) and of flexible sigmoidoscopy screening [60].

\section{Radiation risk in screening}

The topic has been covered in the previous Guideline [11]. Dose-reducing CTC protocols using iterative reconstruction algorithms and lower tube voltage are increasingly being implemented, leading to doses of less than $1 \mathrm{mSv}$ [61].

\section{ECFs in CTC screening}

ECFs may be identified in up to half of asymptomatic screenees [62 -64] with additional work-up required and rising costs for the screening programs. However, when only indeterminate but likely unimportant ("E3") findings and potentially important ("E4") ECFs are considered, the rate is significantly lower. In the European COCOS trial and in a large opportunistic CTC screening series in the USA, the prevalence of E3+E4 ECFs was around $11 \%$, with rates of E4 ECFs being only $1.2 \%-5 \%[2,3$, $51,52]$. Potentially important ECFs included aortic aneurysms, solid or complex cystic renal lesions, pancreatic masses, adnexal masses, and noncalcified lung nodules $>10 \mathrm{~mm}$.

In the PROTEUS trial, findings were reviewed by two experienced radiologists to identify ECFs that needed additional examination. With this approach the prevalence of ECFs requiring further work-up was $1.2 \%$.

\section{Cost and cost-effectiveness of CTC screening}

Costs per participant of a population-based screening program with CTC, including the invitation process, were $€ 169$ in the Netherlands [65] and $€ 197$ in Italy [66]; average costs per participant with advanced neoplasia were respectively $€ 2773$ [65] and $€ 3777$ [66].
Other than average cost per participant, the cost-effectiveness of a screening test is dependent on participation rate and on the number of screening rounds. According to Meulen et al. [67], who based their analysis on unit costs and participation rates in the COCOS trial, CTC was the most cost-effective strategy in participants who underwent more than 2 lifetime screens and was the preferred test for willingness-to-pay thresholds of $€ 3200$ per quality-adjusted life-year (QALY) gained. However, with equal participation, colonoscopy was the preferred test independent of willingness-to-pay thresholds. Meulen et al. [67] did not include ECFs in their cost-effectiveness analysis, stating that long-term follow-up data are lacking. A sensitivity analysis was performed, treating ECFs as pure costs, or potentially cost-saving via detection of aortic aneurysms. In both scenarios CTC remained dominant over colonoscopy assuming more than 2 lifetime screens.

In a recent systematic review, CTC every 5 to 10 years was shown to be more cost-effective than no screening [68]. Robust cost-effectiveness data comparing CTC with stool-based tests, notably FIT, are not yet available.

\section{CTC as a primary screening modality for colorectal cancer: conclusions}

In average-risk individuals, screening CTC achieves an ANDR at least matching those of colonoscopy and flexible sigmoidoscopy, in part secondarily to increased participation. The full impact of ECFs, both medically and economically, remains unknown, although the prevalence of ECFs potentially requiring further work-up is $11 \%$ or less in European screening populations. Sensitivity analysis based on one European screening trial suggests that even when ECFs are incorporated, CTC remains more cost-effective than colonoscopy if more than 2 lifetime screens are done. Full cost - effectiveness data from trials comparing CTC with flexible sigmoidoscopy and FIT are however awaited. Although radiation exposure is a drawback, this disadvantage seems to be overemphasized especially given the current reduction in radiation exposure with CTC.

Based on these considerations, CTC is not recommended as the primary test for population colorectal cancer screening, pending data showing superior efficacy and cost-effectiveness compared to established alternate strategies, notably stoolbased techniques such as FIT. It is recommended as a colorectal cancer screening test on an individual basis, providing the screenees are adequately informed about test characteristics, benefits, and risks.

\section{CCE and screening for colorectal cancer: participation}

A few studies investigated the participation rate for CCE in a colorectal cancer screening population. Participation rates varied from $4.2 \%$ to $17.4 \%$, depending on the design of the study and how CCE was used as screening modality, for example as a primary screening modality or as a filter test [69]. The lowest participation rate of $4.2 \%$ was reported in a German opportunistic screening study where CCE was offered as an alternative to primary optical colonoscopy screening. In another study [70] where CCE was offered to patients who were unwilling to 
undergo optical colonoscopy after a positive FIT, a participation rate of $5 \%$ was found. Although contradictory data on patient preference are available, recent data from a large Danish series of screening individuals suggests CCE was associated with less discomfort than optical colonoscopy and may be preferable to some individuals [71].

\section{CCE in screening: detection rate and yield}

Only a few studies evaluated the role of CCE as a primary screening test. Rex et al. [72] performed a prospective multicenter study including 695 patients to assess CCE accuracy as a primary screening test in an average-risk screening population. CCE sensitivity and specificity for adenomas $\geq 6 \mathrm{~mm}$ were $88 \%$ and $82 \%$, respectively, which seems adequate for patients who cannot undergo colonoscopy or who have had incomplete colonoscopies. Based on these results, a recent multicenter, prospective, randomized study [73] evaluated the diagnostic yield of CCE versus CTC for the identification of colonic polyps in a screening population. Results showed a higher detection rate with CCE (polyps $\geq 6 \mathrm{~mm}, 32 \%$; and polyps $\geq 10 \mathrm{~mm}, 14 \%$ ) compared to CTC (polyps $\geq 6 \mathrm{~mm}, 9 \%$; and polyps $\geq 10 \mathrm{~mm}, 6 \%$ ). The sensitivity of CCE for polyps $\geq 6 \mathrm{~mm}$ (84\%) and polyps $\geq 10 \mathrm{~mm}$ ( $84 \%$ ) was higher compared to CTC ( $32 \%$ and $53 \%$, respectively). Specificity for polyps $\geq 6 \mathrm{~mm}$ was higher for CTC versus CCE (99\% vs. $93 \%$, respectively) and comparable for polyps $\geq 10 \mathrm{~mm}$ ( $99 \%$ vs. $97 \%$, respectively). These observations add additional evidence to previous comparisons demonstrating CCE to have at least noninferior test performance compared to CTC. Based on available evidence, CCE should be considered an acceptable colorectal cancer screening option in appropriately selected patients.

Few studies evaluated the diagnostic yield (detection of polyps and cancer) of CCE in patients with a positive family history of colorectal cancer. Two studies evaluated the role of CCE in screening of first-degree relatives. Parodi et al. [74] showed that CCE sensitivity and specificity for polyps $\geq 6 \mathrm{~mm}$ are $91 \%$ and $88 \%$, respectively, with a PPV and negative predictive value (NPV) of $78 \%$ and $95 \%$, respectively. Moreover, restricting the results to polyps $\geq 10 \mathrm{~mm}$, CCE showed $89 \%$ sensitivity and $95 \%$ specificity. Also Adrián-de-Ganzo et al. [75] in a prospective study of 329 asymptomatic first-degree relatives, randomly assigned to CCE $(n=165)$ or colonoscopy $(n=164)$, assessed screening uptake of CCE vs. colonoscopy. Unexpectedly, $57.4 \%$ of individuals crossed over from the CCE group, and $30.2 \%$ crossed over from the colonoscopy group, meaning that most preferred to undergo colonoscopy. Although the crossover rate between groups was thus significantly higher in the CCE group than in the colonoscopy group, $16.8 \%$ of those who were invited to undergo colonoscopy declined, and when reoffered CCE accepted, and $15.0 \%$ actually underwent CCE. The study confirmed that CCE can be as effective as colonoscopy in detecting significant lesions: these were detected in 14 individuals $(11.7 \%)$ in the CCE group and 13 individuals (11.5\%) in the colonoscopy group (odds ratio [OR] 1.02, $95 \% \mathrm{Cl} 0.45-2.26$; $P=$ $0.96)$. However, the higher crossover rate from the CCE group to the colonoscopy group, mainly due to unwillingness to repeat bowel preparation in the case of a positive result, suggested

better acceptance of screening colonoscopy in this group of patients.

\section{Indications and contraindications to CTC/CCE following positive FOBT/FIT}

RECOMMENDATION

ESGE/ESGAR recommend CTC in the case of a positive FOBT or FIT with incomplete or unfeasible colonoscopy, within organized population screening programs. Strong recommendation, moderate quality evidence. ESGE/ESGAR also suggest the use of CCE in this setting based on availability.

Weak recommendation, moderate quality evidence.

\section{Indications and contraindications for CTC following positive FOBT/FIT}

Fecal blood testing, whether by guaiac-based or immunochemical methods, is predominantly deployed as a population screening test, as it is safe, cheap, well-tolerated and has been proven to reduce colorectal cancer-specific mortality by approximately $15 \%-18 \%$ (for guaiac testing). Although longterm mortality data for FIT screening are awaited, it will likely have even better results due to higher uptake and superior sensitivity for advanced colorectal lesions. More recently, FIT at a low threshold has been advocated as a possible tool to identify patients with colorectal symptoms who are at very low risk of colorectal cancer, and so might avoid the need for further colonic investigation.

Whether derived from a population screening program or via a symptomatic service, patients with positive FOBT or FIT results require further testing to confirm or refute the presence of an underlying cancer or adenoma, permitting subsequent treatment. Colonoscopy combines sensitive diagnosis with therapy by endoscopic resection and is therefore regarded as the preferred test.

However, most patients testing FOBT/FIT-positive will not have advanced neoplasia, meaning that CTC can be considered as a possible triage test to select patients with lesions only of greater size for colonoscopy or surgery. A meta-analysis published in 2014 found 5 studies, together including 622 patients, in whom the average sensitivity of CTC for $\geq 6$-mm adenomas or colorectal cancer was $88.8 \%$, at a specificity of $75.4 \%$ [76]. A more recent study of 50 patients [77] found almost identical results (sensitivity $88.2 \%$, specificity $84.8 \%$ ). However, since the prevalence of $\geq 6$ - $\mathrm{mm}$ polyps is relatively high in this cohort, NPV is less than might be expected, ranging from $85 \%$ to $95 \%$ in the studies included. Moreover, many patients still require colonoscopy after CTC since so many polyps are found; a modeling study concluded that the use of CTC as an intermediate after positive FOBT/FIT can only be cost-effective if the costs of CTC were $\leq 43 \%$ of the costs of colonoscopy [78]. These factors mean that CTC should not be offered routinely to those 
testing FOBT/FIT-positive, and colonoscopy is preferable. One possible exception is where the absolute quantity of fecal blood is low (e.g. quantitative FIT result of $<40$ ), where the prevalence of advanced neoplasia may be sufficiently low to render CTC triage cost-effective. However, to date we are not aware of any studies directly assessing this patient population.

Since CTC has good diagnostic performance, it may be considered for those unwilling to undergo colonoscopy or in whom colonoscopy is unfeasible or incomplete, although screenees should be informed that sensitivity (particularly for smaller adenomas) is inferior to that of colonoscopy and no simultaneous treatment is possible. There is some evidence that offering CTC to those who decline colonoscopy increases uptake of colorectal cancer screening [79].

CTC is safe and well-tolerated in this cohort with a positive fecal blood test [57] and therefore may be preferable in those with contraindications to colonoscopy or judged particularly high risk. Some observational data suggest absolute detection rates may be lower than in healthy screenees who are fit for colonoscopy [80], and post-test cancer rates may be higher [81], although this is probably due to patient factors rather than differences in test sensitivity (i.e., patients who are unfit for colonoscopy are difficult to investigate with any technique, including (TC).

\section{Indications and contraindications for CCE following positive FOBT/FIT}

Three studies were performed comparing the accuracy of CCE and colonoscopy in FIT-positive patients in a colorectal cancer screening setting. In two studies, patients with a positive FIT underwent both CCE and colonoscopy. The primary outcome was to assess the polyp detection rate and accuracy of CCE compared to colonoscopy. The polyp detection rate ranged between $69 \%$ and $74 \%$ for CCE versus $58 \%$ and $64 \%$ for colonoscopy $[69,77,82]$. The study by Holleran et al. [82] showed that the detection rate of significant lesions was comparable between CCE and colonoscopy. However, in the study of KobaekLarsen et al. [69], repeat colonoscopies were performed to explain the high miss rate of colonoscopy. These repeat colonoscopies resulted in the detection of additional polyps, suggesting that the discrepancy in detection rate between CCE and colonoscopy is most likely explained by the falsenegative findings of colonoscopy. In the third study, patients with a positive FIT underwent CCE, CTC, and colonoscopy, using colonoscopy as the reference standard [77]. Both CCE and CTC detected polyps of $\geq 6 \mathrm{~mm}$ and larger with high levels of accuracy. Based on these studies, the sensitivity of CCE for polyps $>9 \mathrm{~mm}$ ranges between $87 \%$ and $92.8 \%$ and the specificity is around $92 \%[69,77]$.

One study investigated the use of CCE in patients unwilling to undergo a colonoscopy after a positive FIT within the colorectal cancer screening program [70]. The aim of this study was to compare CCE and CTC in terms of detection rate as well as participation outcomes. A total of 756 patients were invited to participate of whom only $5 \%$ underwent CCE and $7.4 \%$ underwent CTC, showing that participation for both CCE and CTC after a positive FIT in patients unwilling to undergo colonos- copy is very low. However, the detection rate was higher when using CCE compared to CTC, with $60 \%$ detection of neoplastic lesions in the CCE group compared to $28.6 \%$ in the CTC group.

Finally, only one multicenter prospective study aimed to assess the diagnostic accuracy of CCE-2 for advanced neoplasia in individuals with a positive FIT within an organized screening program [83]. Overall, CCE-2 sensitivity and specificity for advanced neoplasia were $90 \%$ and $66.1 \%$ with PPV and NPV of $57.4 \%$ and $92.9 \%$, respectively, when using a $6-\mathrm{mm}$ cutoff (colonoscopy referral rate $52.8 \%$ ). Sensitivity and specificity were $76.7 \%$ and $90.7 \%$, with PPV and NPV of $80.7 \%$ and $88.4 \%$ when using a $10-\mathrm{mm}$ cutoff (colonoscopy referral rate $32 \%$ ).

In conclusion, these data would support the use of CCE as an alternative to CTC in FIT-positive individuals unwilling to undergo colonoscopy or in whom it is unfeasible.

\section{CTC or CCE following curative-intent resection of colorectal cancer}

\section{RECOMMENDATION}

ESGE/ESGAR suggest CTC with intravenous contrast medium injection for surveillance after curative-intent resection of colorectal cancer only in patients in whom colonoscopy is contraindicated or unfeasible.

Weak recommendation, low quality evidence.

There is insufficient evidence to recommend CCE in this setting.

Very low quality evidence.

Patients with previous colorectal cancer are at increased risk of future colorectal neoplasia, and therefore require surveillance of the remnant colon. Additionally, contrast-enhanced computed tomography (CT) is the mainstay of surveillance for extraluminal local recurrence and remote metastases. Since CTC combines intraluminal assessment with evaluation of the extracolonic structures for locoregional recurrence and remote metastases, it has the potential to simplify follow-up pathways and reduce costs.

Porté et al. [84] conducted a systematic review and metaanalysis of cohort studies which showed that CTC was highly sensitive (95\%, 18/19 cases detected) and $100 \%$ specific for anastomotic recurrence following colorectal cancer resection. Moreover, CTC detected all 10 metachronous cancers in these patients. However, no data were provided regarding diagnostic accuracy for polyps or adenomas; only colorectal cancer was considered.

Three single-center prospective cohort studies [85-87] reported on the diagnostic accuracy of CTC for polyps or adenomas after colorectal cancer resection. The largest study [86] with 550 patients, found that CTC was $81.8 \%$ sensitive for advanced neoplasia (specificity $93.1 \%$ ). However, these studies were of variable quality, with incomplete [87] or delayed [86] comparison to reference standard tests such as colonoscopy for the presence/absence of polyps. 
More recently, a prospective, multicenter, cross-sectional study [88] recruited 231 patients scheduled for colonic surveillance 1 year after curative-intent resection of colorectal cancer. Patients underwent CTC and same-day colonoscopy with segmental unblinding (i.e., sequential revelation of the CTC result to the colonoscopist on a segment-by-segment basis, thereby providing an enhanced reference standard for the presence or absence of neoplasia). The sensitivity of CTC was only $44.0 \%$ for polyps $\geq 6 \mathrm{~mm}$ ( $76.9 \%$ for polyps $\geq 10 \mathrm{~mm}$ ). This is surprisingly low when compared to meta-analyses of the accuracy of CTC in other situations. One possible explanation is the absence of an ileocecal valve in patients with prior right hemicolectomy, thereby permitting gas reflux into the small bowel and reducing the likelihood of optimal colonic distension.

The same cohort of patients was asked which of the two tests they preferred [89]; of the 223 patients who completed their questionnaires, 95 (42.6\%) preferred colonoscopy, 79 (35.4\%) had no preference, and only 49 (22.0\%) preferred CTC.

Limited cost-effectiveness analysis of this cohort, using cost data from a single center, suggests that a CTC-based surveillance strategy is cost-saving relative to colonoscopy; however, as noted above, this comes with the trade-off that fewer adenomas will be detected. Beck et al. [90] estimated that the additional cost for a polyp $\geq 6 \mathrm{~mm}$ detected by using colonoscopy rather than CTC would be $\$ 5700$ ( $€ 4800$ approximately) or $\$ 28000$ ( $€ 24000$ approximately) per additional polyp $\geq 10 \mathrm{~mm}$ detected. Whether these cost data would be replicated in other healthcare systems is uncertain.

\section{Post-polypectomy surveillance}

\section{RECOMMENDATION}

ESGE/ESGAR suggest CTC in patients with high risk polyps undergoing surveillance after polypectomy only when colonoscopy is unfeasible.

Weak recommendation, low quality evidence.

There is insufficient evidence to recommend CCE in postpolypectomy surveillance.

Very low quality evidence.

\section{CTC in post-polypectomy surveillance}

A previous ESGE Guideline in 2013 recommended endoscopic surveillance only for patients with high risk adenomatous lesions (adenomas with high grade dysplasia, or $\geq 10 \mathrm{~mm}$ in size, or $\geq 5$ in number) or serrated lesions ( $\geq 10 \mathrm{~mm}$ in size, or with any degree of cytological dysplasia) [91]. Colonoscopy is considered to be the method of choice for post-polypectomy surveillance, with the primary aim of diagnosing and removing polyps either missed at initial examination or newly developed during the time between the index and follow-up examinations. However, compliance with colonoscopic surveillance is relatively low, ranging from $52 \%$ to $85 \%$, with the highest levels obtained in research settings [92-95]. Moreover, according to a recently published paper [96], adherence to surveillance ESGE guidelines [91] is dramatically low, at only $13.8 \%$.

The impact of FIT on surveillance was recently investigated. Atkin et al. [97] reported that annual low threshold FIT $(10 \mu \mathrm{g} / \mathrm{g})$ with colonoscopy in positive cases had high sensitivity for colorectal cancer and advanced adenomas (sensitivity and specificity were $84.6 \%$ and $70.8 \%$, respectively) and would be cost-saving compared with 3-yearly colonoscopy.

Despite weak evidence supporting CTC for surveillance [98], in patients who are unwilling or unable to undergo colonoscopy, CTC may be a reasonable alternative because of its high sensitivity and NPV for colorectal cancer, outperforming barium enema $[98,99]$.

\section{CCE in post-polypectomy surveillance}

The accuracy of CCE in post-polypectomy surveillance has not been carefully investigated. Only one study investigated CCE as a possible filter test in colonic surveillance in patients scheduled for follow-up colonoscopy [100]. In this study, 102 of 180 patients (57\%) who underwent CCE also underwent a supplemental colonoscopy, because either significant pathology was detected on CCE or CCE examination was incomplete. The completion rate for CCE was $66.7 \%$ and the polyp detection rate was $69 \%$. CCE detected 120 polyps, of which 60 were found at colonoscopy, meaning that half of the detected polyps could not be removed by supplemental colonoscopy. Colonoscopy detected 16 additional polyps that were not found at CCE. More studies are needed to determine the applicability of CCE as a filter test for surveillance colonoscopy after polypectomy. To date, there are not sufficient data to support the use of CCE in post-polypectomy surveillance.

\section{Other indications and contraindications for CTC: diverticular disease, IBD, fragile patient}

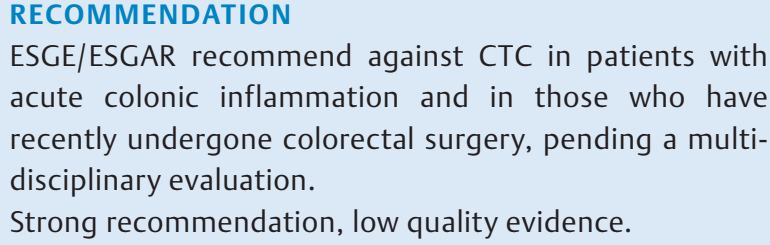
acute colonic inflammation and in those who have recently undergone colorectal surgery, pending a multidisciplinary evaluation.

Strong recommendation, low quality evidence.

In 2006, large surveys from the UK and USA showed CTC was very safe, with symptomatic perforation occurring in approximately 1 in 3000 to 1 in 20000 examinations, and an even lower risk for people undergoing CTC for colorectal cancer screening $[101,102]$. To date there has been no reported death directly attributable to CTC despite its use in routine practice across the world for over a decade.

In 2015, a Japanese national survey of 147439 CTC examinations [58] revealed lower perforation rates of $0.014 \%$ overall, albeit with a higher rate when CTC was used for preoperative staging $(0.028 \%)$; and a much lower rate for screening 
(0.003\%; approximately 1 in 30000 patients). Most patients ( $81 \%)$ with perforation did not require surgical intervention. Vasovagal reaction was reported in $0.081 \%$.

In general, CTC is avoided in patients with acute or subacute colonic mucosal inflammation due to increased risk of colonic perforation [103, 104], difficulty in detecting mucosal dysplasia without biopsies, and inaccurate differentiation of inflammatory polyps or strictures from neoplasia.

A 2014 retrospective study [105] of elderly patients compared 6114 outpatients undergoing initial CTC with 149202 outpatients undergoing initial optical colonoscopy. It found the odds ratio of complications was higher for colonoscopy compared to CTC as follows: lower gastrointestinal bleeding, OR 1.9; other gastrointestinal events, OR 1.35; and cardiovascular events, OR 1.38. Risk of colonic perforation was $0.07 \%$ for CTC and $0.12 \%$ for colonoscopy, but comparisons of perforation risk frequently take no account of asymptomatic perforation in the colonoscopy group (and a large majority of patients with CTCrelated perforation are asymptomatic).

Practical advice for radiologists is given below.

\section{PRACTICAL ADVICE FOR RADIOLOGISTS}

1. CTC is very safe but is absolutely contraindicated in patients with generalized peritonitis, acute bowel perforation, mechanical bowel obstruction, and when a competent patient does not provide consent.

2. Relative contraindications include: healing of localized diverticular perforation; acute inflammatory bowel disease; or younger age (children and young adults).

3. When CTC is requested soon after colonoscopy, particularly after polypectomy, we recommend the CTC radiologist communicates directly with the endoscopist to assess an individual's risk of perforation. Risk factors include large, deep colonic wall defects, mucosal inflammation, and patient comorbidity.

4. If a radiologist believes that bowel perforation may have occurred prior to undertaking CTC, then a standard CT of the abdomen and pelvis should be performed prior to colonic insufflation to help exclude extraluminal gas.

\section{Work-up after CTC and CCE}

RECOMMENDATION

ESGE/ESGAR recommend referral for endoscopic polypectomy in patients with at least one polyp $\geq 6 \mathrm{~mm}$ detected at CTC or CCE.

Follow-up CTC may be clinically considered for 6-9-mm CTC-detected lesions if patients do not undergo polypectomy because of patient choice, comorbidity, and/or low risk profile for advanced neoplasia.

Strong recommendation, moderate quality evidence.
The need for additional endoscopy depends on several clinical characteristics. As it is known that with increasing size, an increasing number of polyps appear to be advanced (i.e., advanced adenoma or carcinoma), polyp size is one of the most important factors [106-108]. In two systematic reviews that included large numbers of polyps, only $1.4 \%$ of lesions $<5 \mathrm{~mm}$ were advanced adenomas and only $0.3 \%$ malignant, while approximately $8 \%$ of $6-9-\mathrm{mm}$ lesions and $80 \%$ of lesions $\geq 10 \mathrm{~mm}$ were advanced neoplasia (the remaining polyps being hyperplastic or inflammatory) [107, 108].

Increasing age and male sex are also associated with a higher risk of advanced neoplasia regardless of polyp size [109]. In the case of subcentimeter lesions, number of lesions (>4), occult blood or overt blood in stool, and pedunculated lesions are associated with a higher risk of advanced neoplasia [110].

The natural history of small polyps detected at CTC has been studied in two prospective observational CTC studies. In the first study, $22 \%$ of 306 polyps increased in size $2-3$ years after the initial CTC, and $6 \%$ became $>10 \mathrm{~mm}$ [111]. However, approximately $28 \%$ of polyps regressed. This was also found in another study, in which $35 \%$ of 95 polyps progressed, and $26 \%$ of polyps regressed (including $15 \%$ with apparent resolution) [19]. None of the regressing polyps were advanced adenomas. Longer follow-up of the lesions is not available.

\section{Follow-up of CTC findings}

In general, it is suggested to consult a gastroenterologist in the case of colorectal findings, to decide whether colonoscopy and/ or follow-up CTC is needed. The gastroenterologist can assess the (future) risk for colorectal cancer based on background risk factors, the actual risk profile, and the possibility of performing colonoscopy in patients with comorbidity. Nevertheless, some general rules can be applied, based on the size of the polyps.

In the case of large polyps ( $\geq 10 \mathrm{~mm}$ ) and suspected masses, colonoscopy should be performed to remove the polyp or take biopsies for a histological diagnosis. In the case of a highly suspicious mass and incomplete colonoscopy without a biopsy (despite optimal bowel preparation and an experienced endoscopist), one could consider treatment without histopathology verification but this should be discussed at a multidisciplinary team.

As stated above, the risk of intermediate polyps (6-9 mm) being advanced neoplasia is low $[106,107]$ and these might remain stable in size or might (completely) regress $[19,111]$. Therefore, in the case of intermediate polyps $(6-9 \mathrm{~mm})$ either a subsequent colonoscopy or a follow-up CTC can be considered, depending on the clinical setting, number of polyps, age, male sex, and comorbidity. Colonoscopy is strongly favored in patients with a genetic predisposition (e.g. Lynch syndrome) and in patients with multiple polyps (>3), while substantial comorbidity favors follow-up CTC.

Lesions $<6 \mathrm{~mm}$ can be mentioned in the CTC report, but the specificity for diminutive lesions is low and the risk of malignancy is low, therefore it is justifiable to ignore them. Radiologists and gastroenterologists should define the local strategy about reporting polyps $<6 \mathrm{~mm}$ in their hospital. 
In the case of a negative colonoscopy following CTC findings a repeat examination should be considered, as in a retrospective study [112] false-negative colonoscopy findings in followup to CTC have been reported in up to $21.5 \%$ (false-negative findings were more common in the right colon). This repeat examination could be a second colonoscopy or a follow-up CTC; an immediate repeat CTC can be considered. To prevent the need for a repeat examination, it is strongly advised to perform a high quality colonoscopy procedure with adequate information on the location of the lesion found on CTC, to be able to perform a "second look" during the initial colonoscopy.

\section{Follow-up of CCE findings}

Regarding findings, most colonic polyps discovered at screening are diminutive, with negligible risk of harboring advanced features (high grade dysplasia, villous component, or malignancy) $[107,108,113,114]$. Moreover, $40 \%$ of diminutive colonic polyps are hyperplastic rather than adenomatous [115]. Diminutive lesions identified by a noninvasive test may also be missed by a subsequent colonoscopy, because of the relatively low sensitivity of the latter for diminutive lesions [116, 117]. By extrapolating data from CTC studies that modelled the impact of colonoscopy or continued surveillance for diminutive polyps discovered at CTC, it can be concluded that referral for removal of diminutive lesions found at CCE might carry an unjustified burden of costs and complications relative to a minimal gain in clinical efficacy [118]. Moreover, studies on second-generation CCE have provided accuracy data in relation to lesions $\geq 6 \mathrm{~mm}$ in size; specificity for diminutive lesions is largely unknown [118].

The only exception regarding post-CCE referral for diminutive polyps is the presence of at least 3 diminutive polyps. Polyp multiplicity has appeared to be a strong predictive factor of subsequent advanced neoplasia development in post-polypectomy follow-up studies [119].

Most advanced neoplasia has been shown to be restricted to the relatively small proportion of patients with polyps $\geq 6 \mathrm{~mm}$ in size [107]. Consequently, post-CCE colonoscopy referral of these patients may be expected to lead to a substantial reduction of the prevalence of advanced neoplasia in patients initially evaluated with CCE. Using a cutoff of significant findings defined as no more than 2 polyps of $10 \mathrm{~mm}, 43 \%$ of patients have avoided colonoscopy; however, high risk findings were detected in only $10.7 \%$ of patients who underwent colonoscopy [100]. This approach entails that small polyps will be left untreated until the subsequent follow-up. Polyps of 6-9 mm may be safely followed for a relatively short period of time [118].

\section{Disclaimer}

ESGE/ESGAR Guidelines represent a consensus of best practice based on the available evidence at the time of preparation. They may not apply to all situations and should be interpreted in the setting of specific clinical situations and resource availability. They are intended to be an educational tool to provide information that may support endoscopists in providing care to patients. They are not rules and should not be utilized to establish a legal standard of care.
This Guideline was reviewed internally by both ESGE and ESGAR, and distributed to ESGE individual members and member societies for comments.

\section{Acknowledgment}

The authors would like to thank Dr Maria Pellisé, Gastroenterology Department (ICMDiM), Hospital Clinic de Barcelona, Spain, and Professor Konstantinos Triantafyllou, Hepatogastroenterology Unit, Attikon University General Hospital, Athens, Greece, for their review of this Guideline.

\section{Competing interests}

D. Burling provides unpaid support to the colon cancer charity, 40tude (not as trustee or officer). E. Dekker has received consultancy honoraria from Fujifilm, Olympus, Tillots, GI Supply, and CPP-FAP, and speakers' fees from Olympus, Roche and GI Supply; she has endoscopic equipment on loan and receives a research grant from Fujifilm; she is on the supervisory board for eNose. R. Eliakim receives a lecture fee and grant support from Medtronic (from 2018 ongoing). I. Fernandez-Urien has provided paid consultancy to Medtronic (20192020). J.E. van Hooft has received lecture fees from Medtronics (from 2014 to 2015 and 2019) and Cook Medical (2019), and consultancy fees from Boston Scientific (2014-2017); her department has received research grants from Cook Medical (2014-2019) and Abbott (2014-2017). M.F. Kaminski provides speaking, teaching, and consultancy services to Olympus (from 2017 ongoing), and speaking and teaching services to Fujifilm, from whom he has equipment on loan (from 2019 ongoing). A. Koulaouzidis received travel support for CEGS meetings from the Jinshan Group $(2018,2019)$; his department was supported by Ankon with an advisory meeting (June 2019); he has received research support from Given Imaging (2010-2011). M.C.W. Spaander receives research support from Medtronic (from 2016 ongoing). C. Spada provides consultancy to Medtronic (from 2016 ongoing). D. Bellini, G. Cappello, C. Carretero, M. de Haan, C. Hassan, A. Laghi, P. Lefere, D. McNamara, T. Mang, S.M. Milluzzo, M. Morrin, E. Neri, S. Pecere, M. Pioche, A. Plumb, D. Regge, E. Rondonotti, J. Stoker, and S. Taylor declare that they have no conflicts of interest.

ESGAR and ESGE covered costs for travel expenses. ESGAR and ESGE did not influence the content of this Guideline.

References

[1] Bray F, Ferlay ], Soerjomataram I et al. Global cancer statistics 2018: GLOBOCAN estimates of incidence and mortality worldwide for 36 cancers in 185 countries. CA Cancer ] Clin 2018; 68: 394-424

[2] Winawer S], Zauber AG, Ho MN et al. Prevention of colorectal cancer by colonoscopic polypectomy. The National Polyp Study Workgroup. N Engl J Med 1993; 329: 1977-1981

[3] Brenner H, Chang-Claude J, Jansen L et al. Reduced risk of colorectal cancer up to 10 years after screening, surveillance, or diagnostic colonoscopy. Gastroenterology 2014; 146: 709-717

[4] Zauber AG, Winawer SJ, O’Brien MJ et al. Colonoscopic polypectomy and long-term prevention of colorectal-cancer deaths. N Engl J Med 2012; 366: 687-696

[5] Rex DK, Boland CR, Dominitz JA et al. Colorectal cancer screening: recommendations for physicians and patients from the U.S. multisociety task force on colorectal cancer. Am J Gastroenterol 2017; 112: $1016-1030$ 
[6] Doubeni CA, Weinmann S, Adams K et al. Screening colonoscopy and risk for incident late-stage colorectal cancer diagnosis in average-risk adults: a nested case-control study. Ann Intern Med 2013; 158 : 312320

[7] Khalid-de Bakker C, Jonkers D, Smits K et al. Participation in colorectal cancer screening trials after first-time invitation: a systematic review. Endoscopy 2011; 43: 1059-1086

[8] Vining D, Galfand D, Bechtold R. Technical feasibility of colon imaging with helical CT and virtual reality [abstract]. AJR Am J Roentgenol 1994; 162: 104

[9] Neri E, Halligan S, Hellström M et al. The second ESGAR consensus statement on CT colonography. Eur Radiol 2013; 23: 720-729

[10] Eliakim R, Fireman Z, Gralnek IM et al. Evaluation of the PillCam Colon capsule in the detection of colonic pathology: results of the first multicenter, prospective, comparative study. Endoscopy 2006; 38: 963-970

[11] Spada C, Stoker J, Alarcon O et al. Clinical indications for computed tomographic colonography: European Society of Gastrointestinal Endoscopy (ESGE) and European Society of Gastrointestinal and Abdominal Radiology (ESGAR) Guideline. Eur Radiol 2015; 25: 331-345

[12] Spada C, Hassan C, Galmiche JP et al. Colon capsule endoscopy: European Society of Gastrointestinal Endoscopy (ESGE) Guideline. Endoscopy 2012; 44: 527-536

[13] Richardson WS, Wilson MC, Nishikawa J et al. The well-built clinical question: a key to evidence-based decisions. ACP J Club 1995; 123: A12-A13

[14] Guyatt GH, Oxman AD, Vist GE et al. GRADE: an emerging consensus on rating quality of evidence and strength of recommendations. BM] 2008; 336: 924-926

[15] Atkins D, Best D, Briss PA et al. Grading quality of evidence and strength of recommendations. BMJ 2004; 328: 1490 doi:10.1136/ bmj.328.7454.1490

[16] Dumonceau J-M, Hassan C, Riphaus A et al. European Society of Gastrointestinal Endoscopy (ESGE) Guideline Development Policy. Endoscopy 2012; 44: 626-629

[17] Sali L, Mascalchi M, Falchini M et al. Reduced and full-preparation CT colonography, fecal immunochemical test, and colonoscopy for population screening of colorectal cancer: a randomized trial. J Natl Cancer Inst 2015; 108: djv319

[18] Regge D, lussich G, Segnan N et al. Comparing CT colonography and flexible sigmoidoscopy: a randomised trial within a population-based screening programme. Gut 2017; 66: 1434-1440

[19] Nolthenius CJT, Boellaard TN, de Haan MC et al. Evolution of screendetected small $(6-9 \mathrm{~mm})$ polyps after a 3-year surveillance interval: assessment of growth with $\mathrm{CT}$ colonography compared with histopathology. A J Gastroenterol 2015; 110: 1682-1690

[20] Obaro AE, Plumb AA, Fanshawe TR et al. Post-imaging colorectal cancer or interval cancer rates after $\mathrm{CT}$ colonography: a systematic review and meta-analysis. Lancet Gastroenterol Hepatol 2018; 3: 326-336

[21] Nagata K, Endo S, Honda T et al. Accuracy of CT colonography for detection of polypoid and non-polypoid neoplasia by gastroenterologists and radiologists: a nationwide multicenter study in Japan. Am J Gastroenterol 2017; 112: 163-171

[22] Halligan S, Dadswell E, Wooldrage K et al. Computed tomographic colonography compared with colonoscopy or barium enema for diagnosis of colorectal cancer in older symptomatic patients: two multicenter randomised trials with economic evaluation (the SIGGAR trials). Health Technol Assess 2015; 19: 1-134

[23] Maaser C, Sturm A, Vavricka SR et al. ECCO-ESGAR Guideline for diagnostic assessment in IBD Part 1: Initial diagnosis, monitoring of known IBD, detection of complications. J Crohns Colitis 2019; 13: $144-164$
[24] Flor N, Mezzanzanica M, Rigamonti P et al. Contrast-enhanced computed tomography colonography in preoperative distinction between T1-T2 and T3-T4 staging of colon cancer. Acad Radiol 2013; 20: 590595

[25] Horvat N, Raj A, Ward JM et al. Clinical value of CT colonography versus preoperative colonoscopy in the surgical management of occlusive colorectal cancer. AJR Am J Roentgenol 2018; 210: 333-340

[26] Flor N, Zanchetta E, Di Leo G et al. Synchronous colorectal cancer using CT colonography vs. other means: a systematic review and meta-analysis. Abdom Radiol 2018; 43: 3241-3249

[27] Atkin W, Dadswell E, Wooldrage K et al. Computed tomographic colonography versus colonoscopy for investigation of patients with symptoms suggestive of colorectal cancer (SIGGAR): a multicentre randomised trial. Lancet 2013; 381: 1194-1202

[28] Poston G], Tait D, O'Connell S et al. Diagnosis and management of colorectal cancer: summary of NICE guidance. BM] 2011; 343: d6751-d6751

[29] O'Shea A, Foran A, Murray T et al. Quality of same day CT colonography following incomplete optical colonoscopy. Eur Radiol 2020: doi:10.1007/s00330-020-06979-3

[30] Chang K], Rekhi SS, Anderson SW et al. Fluid tagging for CT colonography: effectiveness of a 2-hour iodinated oral preparation after incomplete optical colonoscopy. J Comput Assist Tomogr 2011; 35: 91 95

[31] Theis ], Kim DH, Lubner MG et al. CT colonography after incomplete optical colonoscopy: bowel preparation quality at same-day vs. deferred examination. Abdom Radiol (NY) 2016; 41: 10-18

[32] Saluja S, Gaikstas G, Sapundzieski M. Optimal timing for faecal tagging in same day $\mathrm{CT}$ colonography for patients with failed colonoscopy. Radiography (Lond) 2017; 23: e47-e49

[33] O'Shea A, Murray T, Morrin MM et al. Incidence of clinically significant perforation at low dose non-contrast $\mathrm{CT}$ and its value prior to same day $\mathrm{CT}$ colonography following incomplete colonoscopy. Abdom Radiol (NY) 2020; 45: 1044-1048

[34] Lara LF, Avalos D, Huynh H et al. The safety of same-day CT colonography following incomplete colonoscopy with polypectomy. United European Gastroenterol J 2015; 3: 358-363

[35] Baltes P, Bota M, Albert J et al. PillCamColon2 after incomplete colonoscopy - A prospective multicenter study. World J Gastroenterol 2018; 24: 3556-3566

[36] Hussey M, Holleran G, Stack R et al. Same-day colon capsule endoscopy is a viable means to assess unexplored colonic segments after incomplete colonoscopy in selected patients. United European Gastroenterol J 2018; 6: 1556-1562

[37] Nogales Ó, García-Lledó J, Luján M et al. Therapeutic impact of colon capsule endoscopy with PillCam ${ }^{\mathrm{TM}}$ COLON 2 after incomplete standard colonoscopy: a Spanish multicenter study. Rev Esp Enferm Dig 2017; 109: 322-327

[38] Toth E, Yung DE, Nemeth A et al. Video capsule colonoscopy in routine clinical practice. Ann Transl Med 2017; 5: 195-195

[39] Spada C, Hassan C, Barbaro B et al. Colon capsule versus CT colonography in patients with incomplete colonoscopy: a prospective, comparative trial. Gut 2015; 64: 272-281

[40] Negreanu L, Smarandache G, Mateescu RB. Role of capsule endoscopy Pillcam COLON 2 in patients with known or suspected Crohn's disease who refused colonoscopy or underwent incomplete colonoscopic exam: a case series. Tech Coloproctol 2014; 18: 277-283

[41] Negreanu L, Babiuc R, Bengus A et al. PillCam Colon 2 capsule in patients unable or unwilling to undergo colonoscopy. World ] Gastrointest Endosc 2013; 5: 559-567

[42] Triantafyllou K, Viazis N, Tsibouris P et al. Colon capsule endoscopy is feasible to perform after incomplete colonoscopy and guides further workup in clinical practice. Gastrointest Endosc 2014; 79: 307-316 
[43] Alarcón-Fernández O, Ramos L, Adrián-de-Ganzo Z et al. Effects of colon capsule endoscopy on medical decision making in patients with incomplete colonoscopies. Clin Gastroenterol Hepatol 2013; 11: 534-540.e1

[44] Pioche M, de Leusse A, Filoche B et al. Prospective multicenter evaluation of colon capsule examination indicated by colonoscopy failure or anesthesia contraindication. Endoscopy 2012; 44: 911-916

[45] Jellema P, van der Windt DAWM, Bruinvels DJ et al. Value of symptoms and additional diagnostic tests for colorectal cancer in primary care: systematic review and meta-analysis. BMJ 2010; 340: c1269

[46] Pickhardt PJ, Correale L, Delsanto S et al. CT colonography performance for the detection of polyps and cancer in adults $\geq 65$ years old: systematic review and meta-analysis. AJR Am J Roentgenol 2018; 211: 40-51

[47] Pickhardt PJ, Correale L, Morra L et al. Extracolonic findings at CT colonography: systematic review and meta-analysis. AJR Am J Roentgenol 2018; 211: 25-39

[48] Halligan S, Wooldrage K, Dadswell E et al. Identification of extracolonic pathologies by computed tomographic colonography in colorectal cancer symptomatic patients. Gastroenterology 2015; 149: 89101.e5

[49] Cha JM, Kozarek RA, La Selva D et al. Risks and benefits of colonoscopy in patients 90 years or older, compared with younger patients. Clin Gastroenterol Hepatol 2016; 14: 80-86.e1

[50] Stoop EM, de Haan MC, de Wijkerslooth TR et al. Participation and yield of colonoscopy versus non-cathartic CT colonography in population-based screening for colorectal cancer: a randomised controlled trial. Lancet Oncol 2012; 13: 55-64

[51] Sali L, Regge D. CT colonography for population screening of colorectal cancer: hints from European trials. Br J Radiol 2016; 89: 20160517

[52] Senore C, Correale L, Regge D et al. Flexible sigmoidoscopy and CT colonography screening: patients' experience with and factors for undergoing screening-insight from the PROTEUS colon trial. Radiology 2018; 286: 873-83

[53] Tutein Nolthenius C], Boellaard TN, de Haan MC et al. Computer tomography colonography participation and yield in patients under surveillance for 6-9 mm polyps in a population-based screening trial. Eur Radiol 2016; 26: 2762-2770

[54] Leggett B, Whitehall V. Role of the serrated pathway in colorectal cancer pathogenesis. Gastroenterology 2010; 138: 2088-2100

[55] Sali L, Ventura L, Grazzini G et al. Patients' experience of screening CT colonography with reduced and full bowel preparation in a randomised trial. Eur Radiol 2019; 29: 2457-2464

[56] Pendsé DA, Taylor SA. Complications of CT colonography: a review. Eur J Radiol 2013; 82: 1159-1165

[57] Plumb AA, Ghanouni A, Rees C] et al. Patient experience of CT colonography and colonoscopy after fecal occult blood test in a national screening programme. Eur Radiol 2017; 27: 1052-1063

[58] Nagata K, Takabayashi K, Yasuda T et al. Adverse events during CT colonography for screening, diagnosis and preoperative staging of colorectal cancer: a Japanese national survey. Eur Radiol 2017; 27: 4970-4978

[59] Bellini D, Rengo M, De Cecco CN et al. Perforation rate in CT colonography: a systematic review of the literature and meta-analysis. Eur Radiol 2014; 24: 1487-1496

[60] Holme $\varnothing$, Bretthauer M, Fretheim A et al. Flexible sigmoidoscopy versus faecal occult blood testing for colorectal cancer screening in asymptomatic individuals. Cochrane Database Syst Rev 2013: CD009259

[61] Kang H-J, Kim SH, Shin C-I et al. Sub-millisievert CT colonography: effect of knowledge-based iterative reconstruction on the detection of colonic polyps. Eur Radiol 2018; 28: 5258-5266
[62] Chin M, Mendelson R, Edwards J et al. Computed tomographic colonography: prevalence, nature, and clinical significance of extracolonic findings in a community screening program. Am J Gastroenterol 2005; 100: 2771-2776

[63] Veerappan GR, Ally MR, Choi J-HR et al. Extracolonic findings on CT colonography increases yield of colorectal cancer screening. AJR Am J Roentgenol 2010; 195: 677-686

[64] Kim YS, Kim N, Kim SY et al. Extracolonic findings in an asymptomatic screening population undergoing intravenous contrast-enhanced computed tomography colonography. J Gastroenterol Hepatol 2008; $23:$ e $49-57$

[65] de Haan MC, Thomeer M, Stoker ] et al. Unit costs in population-based colorectal cancer screening using CT colonography performed in university hospitals in The Netherlands. Eur Radiol 2013; 23: 897-907

[66] Mantellini P, Lippi G, Sali L et al. Cost analysis of colorectal cancer screening with CT colonography in Italy. Eur J Health Econ 2018; 19: 735-746

[67] van der Meulen MP, Lansdorp-Vogelaar I, Goede SL et al. Colorectal cancer: cost-effectiveness of colonoscopy versus $\mathrm{CT}$ colonography screening with participation rates and costs. Radiology 2018; 287 : 901-911

[68] Ran T, Cheng C-Y, Misselwitz B et al. Cost-effectiveness of colorectal cancer screening strategies - a systematic review. Clin Gastroenterol Hepatol 2019; 17: 1969-1981.e15

[69] Kobaek-Larsen M, Kroijer R, Dyrvig A-K et al. Back-to-back colon capsule endoscopy and optical colonoscopy in colorectal cancer screening individuals. Colorectal Dis 2018; 20: 479-485

[70] Pioche M, Ganne C, Gincul R et al. Colon capsule versus computed tomography colonography for colorectal cancer screening in patients with positive fecal occult blood test who refuse colonoscopy: a randomized trial. Endoscopy 2018; 50: 761-769

[71] Thygesen MK, Baatrup G, Petersen C et al. Screening individuals' experiences of colonoscopy and colon capsule endoscopy; a mixed methods study. Acta Oncol 2019; 58: (Suppl. 01): S71-S76

[72] Rex DK, Adler SN, Aisenberg J et al. Accuracy of capsule colonoscopy in detecting colorectal polyps in a screening population. Gastroenterology 2015; 148: 948-957.e2

[73] Cash BD, Fleisher MR, Fern S et al. A multicenter, prospective, randomized study comparing the diagnostic yield of colon capsule endoscopy versus computed tomographic colonography in a screening population. Results of the TOPAZ study. Gastrointest Endosc 2019; 89: AB87-AB88

[74] Parodi A, Vanbiervliet G, Hassan C et al. Colon capsule endoscopy to screen for colorectal neoplasia in those with family histories of colorectal cancer. Gastrointest Endosc 2018; 87: 695-704

[75] Adrián-de-Ganzo Z, Alarcón-Fernández O, Ramos L et al. Uptake of colon capsule endoscopy vs colonoscopy for screening relatives of patients with colorectal cancer. Clin Gastroenterol Hepatol 2015; 13 : 2293-2301.e1

[76] Plumb AA, Halligan S, Pendsé DA et al. Sensitivity and specificity of CT colonography for the detection of colonic neoplasia after positive faecal occult blood testing: systematic review and meta-analysis. Eur Radiol 2014; 24: 1049-1058

[77] Rondonotti E, Borghi C, Mandelli G et al. Accuracy of capsule colonoscopy and computed tomographic colonography in individuals with positive results from the fecal occult blood test. Clin Gastroenterol Hepatol 2014; 12: 1303-1310

[78] Lansdorp-Vogelaar I, van Ballegooijen M, Zauber AG et al. At what costs will screening with $\mathrm{CT}$ colonography be competitive? A cost-effectiveness approach Int J Cancer 2009; 124: 1161-1168

[79] Sali L, Grazzini G, Ventura L et al. Computed tomographic colonography in subjects with positive faecal occult blood test refusing optical colonoscopy. Dig Liver Dis 2013; 45: 285-289 
[80] Plumb AA, Halligan S, Nickerson C et al. Use of CT colonography in the English Bowel Cancer Screening Programme. Gut 2014; 63: 964-973

[81] Derbyshire E, Hungin P, Nickerson C et al. Colonoscopic perforations in the English National Health Service Bowel Cancer Screening Programme. Endoscopy 2018; 50: 861-870

[82] Holleran G, Leen R, O’Morain C et al. Colon capsule endoscopy as possible filter test for colonoscopy selection in a screening population with positive fecal immunology. Endoscopy 2014; 46: 473-478

[83] Pecere S, Senore C, Hassan C et al. Accuracy of colon capsule endoscopy for advanced neoplasia. Gastrointest Endosc 2020; 91: 406-414. e1

[84] Porté F, Uppara M, Malietzis G et al. CT colonography for surveillance of patients with colorectal cancer: Systematic review and meta-analysis of diagnostic efficacy. Eur Radiol 2017; 27: 51-60

[85] Amitai MM, Fidder H, Avidan B et al. Contrast-enhanced CT colonography with 64-slice MDCT compared to endoscopic colonoscopy in the follow-up of patients after colorectal cancer resection. Clin Imaging 2009; 33: 433-438

[86] Kim HJ, Park SH, Pickhardt PJ et al. CT colonography for combined colonic and extracolonic surveillance after curative resection of colorectal cancer. Radiology 2010; 257: 697-704

[87] Neri E, Vagli P, Turini F et al. Post-surgical follow-up of colorectal cancer: role of contrast-enhanced CT colonography. Abdom Imaging 2010; 35: 669-675

[88] Weinberg DS, Pickhardt PJ, Bruining DH et al. Computed tomography colonography vs colonoscopy for colorectal cancer surveillance after surgery. Gastroenterology 2018; 154: 927-934.e4

[89] Weinberg DS, Mitnick J, Keenan E et al. Post-operative colorectal cancer surveillance: preference for optical colonoscopy over computerized tomographic colonography. Cancer Causes Control 2019; 30 : 1269-1273

[90] Beck JR, Ross EA, Kuntz KM et al. Yield and cost-effectiveness of computed tomography colonography versus colonoscopy for post colorectal cancer surveillance. MDM Policy \& Practice 2018; 3 : 238146831881051

[91] Hassan C, Quintero E, Dumonceau J-M et al. Post-polypectomy colonoscopy surveillance: European Society of Gastrointestinal Endoscopy (ESGE) Guideline. Endoscopy 2013; 45: 842-864

[92] Colquhoun P, Chen H-C, Kim Jl et al. High compliance rates observed for follow up colonoscopy post polypectomy are achievable outside of clinical trials: efficacy of polypectomy is not reduced by low compliance for follow up. Colorectal Dis 2004; 6: 158-161

[93] Taylor DP, Cannon-Albright LA, Sweeney C et al. Comparison of compliance for colorectal cancer screening and surveillance by colonoscopy based on risk. Genet Med 2011; 13: 737-743

[94] Rapuri S, Spencer J, Eckels D. Importance of postpolypectomy surveillance and postpolypectomy compliance to follow-up screening review of literature. Int J Colorectal Dis 2008; 23: 453-459

[95] Cooper GS, Kou TD, Barnholtz Sloan JS et al. Use of colonoscopy for polyp surveillance in Medicare beneficiaries. Cancer 2013; 119: 1800-1807

[96] Koh FH, Chan DKH, $\mathrm{Ng}$ J et al. Adherence to surveillance guidelines following colonic polypectomy is abysmal. J Gastrointest Oncol 2019; 10: $166-170$

[97] Atkin W, Cross AJ, Kralj-Hans I et al. Faecal immunochemical tests versus colonoscopy for post-polypectomy surveillance: an accuracy, acceptability and economic study. Health Technol Assess 2019; 23: $1-84$

[98] Regge D, Laudi C, Galatola G et al. Diagnostic accuracy of computed tomographic colonography for the detection of advanced neoplasia in individuals at increased risk of colorectal cancer. JAMA 2009; 301: 2453-2461
[99] Sosna J, Sella T, Sy O et al. Critical analysis of the performance of double-contrast barium enema for detecting colorectal polyps > or $=6 \mathrm{~mm}$ in the era of CT colonography. AJR Am J Roentgenol 2008; 190: 374-385

[100] Kroijer R, Kobaek-Larsen M, Qvist N et al. Colon capsule endoscopy for colonic surveillance. Colorectal Dis 2019; 21: 532-537

[101] Burling D, Halligan S, Slater A et al. Potentially serious adverse events at CT colonography in symptomatic patients: national survey of the United Kingdom. Radiology 2006; 239: 464-471

[102] Pickhardt PJ. Incidence of colonic perforation at CT colonography: review of existing data and implications for screening of asymptomatic adults. Radiology 2006; 239: 313-316

[103] Prabhakar N, Kalra N, Bhasin DK et al. Comparison of CT colonography with conventional colonoscopy in patients with ulcerative colitis. Acad Radiol 2015; 22: 296-302

[104] Silvestre J, del Sánchez-Lauro MM, del Callejón MM et al. Pneumoperitoneum after $\mathrm{CT}$ colonography in a patient with ulcerative colitis. Rev Esp Enferm Dig 2015; 107: 456-457

[105] Zafar HM, Harhay MO, Yang J et al. Adverse events following computed tomographic colonography compared to optical colonoscopy in the elderly. Prev Med Rep 2014; 1: 3-8

[106] Ponugoti PL, Cummings OW, Rex DK. Risk of cancer in small and diminutive colorectal polyps. Dig Liver Dis 2017; 49: 34-37

[107] Hassan C, Pickhardt PJ, Kim DH et al. Systematic review: distribution of advanced neoplasia according to polyp size at screening colonoscopy. Aliment Pharmacol Ther 2010; 31: 210-217

[108] Lieberman D, Moravec M, Holub J et al. Polyp size and advanced histology in patients undergoing colonoscopy screening: implications for CT colonography. Gastroenterology 2008; 135: 1100-1105

[109] Hassan C, Pooler BD, Kim DH et al. Computed tomographic colonography for colorectal cancer screening: risk factors for the detection of advanced neoplasia. Cancer 2013; 119: 2549-2554

[110] Kolligs FT, Crispin A, Graser A et al. Risk factors for advanced neoplasia within subcentimetric polyps: implications for diagnostic imaging. Gut 2013; 62: 863-870

[111] Pickhardt PJ, Kim DH, Pooler BD et al. Assessment of volumetric growth rates of small colorectal polyps with CT colonography: a longitudinal study of natural history. Lancet Oncol 2013; 14: 711720

[112] Pooler BD, Kim DH, Weiss JM et al. Colorectal polyps missed with optical colonoscopy despite previous detection and localization with CT colonography. Radiology 2016; 278: 422-429

[113] Bond JH. Clinical relevance of the small colorectal polyp. Endoscopy 2001; 33: 454-457

[114] Church JM. Clinical significance of small colorectal polyps. Dis Colon Rectum 2004; 47: 481-485

[115] Weston AP, Campbell DR. Diminutive colonic polyps: histopathology, spatial distribution, concomitant significant lesions, and treatment complications. Am J Gastroenterol 1995; 90: 24-28

[116] van Rijn JC, Reitsma JB, Stoker J et al. Polyp miss rate determined by tandem colonoscopy: a systematic review. Am J Gastroenterol 2006 101: $343-350$

[117] Rex DK, Cutler CS, Lemmel GT et al. Colonoscopic miss rates of adenomas determined by back-to-back colonoscopies. Gastroenterology $1997 ; 112: 24-28$

[118] Spada C, Hassan C, Galmiche JP et al. Colon capsule endoscopy: European Society of Gastrointestinal Endoscopy (ESGE) Guideline. Endoscopy 2012; 44: 527-536

[119] Martínez ME, Baron JA, Lieberman DA et al. A pooled analysis of advanced colorectal neoplasia diagnoses after colonoscopic polypectomy. Gastroenterology 2009; 136: 832-841 